(To the Editors of the Journal of the Institute of Actuaries)

SIRS,

\title{
The Curve of Deaths
}

In the course of the discussion on Mr Phillips's paper, I pointed out that $\mathrm{Mr}$ Phillips was mistaken in stating that his formula departed from a "dictum" of Woolhouse, but on reading the author's written reply to points raised by the discussion it seems that I failed to make my argument clear. I shall be glad therefore if you will allow me the opportunity of setting it out more fully.

The part of $\mathrm{Mr}$ Phillips's paper to which I referred reads as follows (F.I.A. Vol. Lxvi, pp. 27-28):

"Woolhouse... in a paper 'On Integration by means of Selected Values of the Function' ( $\mathcal{Y} . I . A$. Vol. xxvI, p. r22)... laid it down that: '... if formulas of the same kind are to be successfully applied to assurance calculations, it is indispensable to have to deal with values exclusively appertaining to integral years of age'. So far as can be ascertained this dictum has been consistently followed ever since. It is now proposed to depart from it."

Both the title of Woolhouse's paper and the context show that by a "formula of the same kind " was meant a formula expressing the value of a definite integral in terms of values of the integrand. Now Mr Phillips's formula expresses the integral in terms not of the integrand, but of another function; hence it is not a "formula of the same kind", and what Woolhouse laid down cannot apply to it.

The implication of Mr Phillips's statement is that he has proved Woolhouse to have been at fault. I have explained, however, that he has not done so, and in fact, as I remarked during the discussion, so far from anything of the kind, the idea which forms the underlying principle of Mr Phillips's formula was used by Woolhouse for his method of approximate valuation.

Nothing I have written is intended to belittle the merits of the formula itself, which, as I hope I made clear at the meeting, I consider to be of very great value.

$$
\text { I am, Sirs, etc., }
$$

C. D. RICH

25/3I, MoORgate, E.C. 2

7th Fune 1935 